\title{
Re-Contextualizing Medical Pluralism in South Africa: a Research Schema for Indigenous Decision Making
}

\author{
Christopher J. Burman ${ }^{1}$ (D)
}

Published online: 5 July 2018

(C) The Author(s) 2018

\begin{abstract}
The purpose of this article is to explain the rationale and development of a research schema that focuses on reducing the unintended consequences of medical pluralism in the context of communicable and non-communicable diseases in eastern and southern Africa. The research schema represents a contribution to the field of action-oriented research relating to the unintended consequences associated with medical pluralism that will be piloted in South Africa. The principle consequences of the unintended consequences of medically pluralism are delays in testing and treatment interruption. The research schema is framed through a resilience lens because the unintended consequences of medical pluralism bear the hallmarks of a complex 'wicked problem'. The resilience perspective will use grassroots agency as the initial referential axis of enquiry. From this start point, broader systemic influences will be contextualized from a realist perspective using the 'AART' model of enquiry as a guiding heuristic ('abduction, abstraction, retroduction and testing'). The 'abductive' component of the 'AART' model will facilitate a re-interrogation of broader systemic influences that sustain contemporary forms of medical pluralism as a precursor to the action-oriented phases. The methodological approach will include the application of proprietary software called SenseMaker ${ }^{\circledR}$ which was designed to enable research into complex anthropogenic phenomena. Analytically the re-interrogation aims to 'empower indigenous decision making alongside scientific data' as a mechanism to develop novel social practices that can reduce the unintended consequences associated with medical pluralism. The forthcoming pilot will ultimately be the judge of this theoretical contribution.
\end{abstract}

Keywords 'AART' · Complexity · Core organizing principle · Polymorphic signifier · SenseMaker® The 'origins of HIV'

Electronic supplementary material The online version of this article (https://doi.org/10.1007/s11213-0189460-0) contains supplementary material, which is available to authorized users.

Christopher J. Burman

burmanc@edupark.ac.za

1 The Rural Development and Innovation Hub (affiliated to the Turfloop Graduate School of

Leadership), University of Limpopo, Private Bag X1106, Limpopo Province, Sovenga 0727, South Africa 


\section{Introduction}

The research schema that is described below aims to re-interrogate the way in which the pluralistic health care environment in South Africa influences wellness in the context of both communicable and non-communicable diseases from the perspective of indigenous treatment seeking decision making and health seeking behavior. The research schema has been developed through earlier work that focused on the HIV and AIDS epidemic in South Africa (Burman and Aphane 2016b). Medical pluralism refers to the co-existence of multiple health care sectors within a particular geographical area which is "found in almost every country in the world" (WHO 2013, p 7). Over the last 15 years, there has been a steady flow of peer reviewed reports relating to the unintended health-related consequences associated with medical pluralism in eastern and southern Africa. In the context of HIV, medical pluralism is primarily associated with delays in testing and treatment interruption (for one of many examples, see Moshabela et al. 2017).

There is now a consensus that (1) the drivers of the unintended consequences associated with medical pluralism are a combination of interdependent factors that are mostly framed through technical, biomedical lenses (Heestermans et al. 2016) and, (2) the most promising way to reduce the influence of this cycle is to improve the levels of collaboration between, of full integration of, the traditional and biomedical health sectors (for examples see, Audet et al. 2017; Leclerc-Madlala et al. 2016; Zuma et al. 2018). Despite the commitments to increased collaboration, realities on the ground suggest "medical cohabitation rather than truly integrated medical systems" remains the norm in sub-Saharan Africa (Gyasi et al. 2018, p 2) — and, on the few occasions, when collaborative efforts have been achieved, they have tended to be "short-lived" (Leclerc-Madlala et al. 2016, p 186).

The research schema takes an alternative perspective which is influenced by plausible weaknesses within the two statements provided above. The first critique is that by applying a predominantly technical, biomedical mind-set to alter a system that is sustained by beliefs and value systems that are variably distributed within a dispositional African context overlooks the systemic perspective that the World Health Organization (WHO) has been promoting for almost a decade. The (WHO 2009, p 19) argued that health systems are complex systems that are "constantly changing, with components that are tightly connected and highly sensitive to change elsewhere in the system. They are nonlinear, unpredictable and resistant to change, with seemingly obvious solutions sometimes worsening a problem". From the perspective of the research schema, this complexity represents a justification for considering the plausibility that medical pluralism contains sufficient nonlinearity to warrant a qualitatively different mode of enquiry.

The second critique is the assumption that improving the structural relationships between the 'cohabiting' health providers will necessarily reduce the unintended consequences. Whilst there is a logic to this suggestion, there is limited empirical evidence to support the argument (LeclercMadlala et al. 2016). Influenced by the WHO's shift from a health sector to health systems perspective and structuration theory (Giddens 1984), the research schema assumes an alternative perspective that focuses on the agency of indigenous decision makers as a systemic referential axis of enquiry because both agency and structure influence the 'constitution of society'.

The alternative perspective aims to identify potential strategies to reduce the unintended health impacts by initially focusing on indigenous decision making and subsequent health seeking behaviors of clients (i.e., the agency of patients), rather than being reliant on waiting for an improvement in the structural relationship/s between the 'cohabiting' health sectors. The alternative position is framed through the following sub-perspectives: (1) the pluralistic health 
care environment in South Africa as being sufficiently nonlinear for it to be framed as a complex challenge, thus should be responded to accordingly; (2) the clients within the system being intentional agents who have the potentials to change system dynamics, irrespective of the relationship/s between the 'cohabiting' health sectors, and (3) that the sustained presence of the unintended consequences associated with medical pluralism reflects the characteristics of a 'wicked problem'.

'Wicked problems' have been described as "any complex issue which defies complete definition and for which there can be no final solution" (Brown et al. 2010, p 302). The implicit 'wickedness' of medical pluralism reflects the tendency of the system to return to its original condition in spite of interventions designed to improve it when only the structural referential axis is used as the loci of change. The tendency of systems to return to their original condition is attributed to the nonlinear relationships that are embedded within complex systems (Burman and Aphane 2017). The nonlinear interconnections that sustain these types of system enables them "to reorganize and recover from change and disturbance [i.e., externally imposed interventions] without changing to other states" (Ahern 2011, p 341). Consequently, a research schema that is designed on the basis that complex systems are able to return to their original condition after the "removal of, [or changes within, some] parts by adapting to the change" represents a pragmatic methodological stance (Rickles et al. 2007, p 933).

The article is structured in the following way: first, a summary of the community-university partnership which has developed resilience to two unintended consequences associated with medical pluralism is provided in order to demonstrate that it is possible to build resilience without immediate recourse to either of the 'cohabiting' health sectors. This is followed by a synopsis of the pluralistic health care environment in South Africa, using disease causation and the 'origins of HIV' as an exemplar. Third, the design of the SenseMaker® instrument, followed by a summary of the implementation details is provided. The concluding comments return to the 'wicked problem' theme and argue that as there is no clear cut solution to the unintended consequences associated with medical pluralism, an alternative, action-oriented resilience strategy is a justifiable mode of enquiry.

\section{The Community-University Partnership}

In 2013 a community-university partnership in the Waterberg district, Limpopo Province, South Africa began an action-oriented research initiative which was designed to align HIVrelated educational and awareness materials with UNAIDS' (2014) 90-90-90 strategy to end AIDS by 2030. One unexpected finding that emerged during the initiative was a theme that was labelled the 'origins of HIV' (Burman and Aphane 2016a). In the language of complexity, the 'origins of HIV' represents a local manifestation of a "core organizing principle [or] attractor" (Sturmberg and Martin 2010, p 527) which was adversely influencing health seeking behaviors among traditionalists living with HIV (Burman and Aphane 2016a). Three years later, the 'origins of HIV' has become the foundation of an educational and awareness package which is contributing to a sustained increase in adherence to antiretroviral therapy (ART) and a reduction in internalized stigma among rural people influenced by medical pluralism living with HIV (Burman and Aphane 2016b). This has resulted in a localized reduction in two national health priority areas (SANAC 2017) without any interaction with the 'cohabiting' health sectors. 


\section{Reducing the Unintended Consequences of Medical Pluralism: A Nonlinear Perspective}

The bulk of the contemporary literature relating to medical pluralism recommends improving the structural relationship/s between the 'cohabiting' health sectors as a mechanism to reduce the unintended consequences because it could provide patients with a "truly holistic and comprehensive form of [African] care" (Moshabela et al. 2016, p 89). The logic of these recommendations are based on the linear argument that if the influence of the drivers of the unintended consequences are reduced (in this instance the structural relationship/s between the 'cohabiting' health sectors), the unintended consequences will also, necessarily, decline which will lead to "an ultimate improvement in HIV patient care in rural South Africa" (Audet et al. 2017, p 5).

The linear logic of this type of approach only remains coherent if the system that sustains the unintended consequences is a linear system. As has been suggested, above, it is plausible that medical pluralism is sustained by some nonlinearity, thus should be responded to accordingly. One example of the nonlinearity contained within the pluralistic health care environment in South Africa - disease causation - is presented below.

\section{A Plausible Nonlinear Driver: Disease Causation}

In 1948 the WHO defined 'health' as "a state of complete physical, mental, and social wellbeing and not merely the absence of disease or infirmity" (WHO 1946). However, there are varying beliefs - or "cosmologies" (De Roubaix 2016, p159) - that influence health seeking behavior which includes two dominant ideal-type categories that are premised upon one underlying dynamic: disease causation (Dubois 1961).

In sub-Saharan Africa, two dominant ideal-type categories manifest through western and ethno-medicine aetiological frames (Legare and Gelman 2008). The western aetiological idealtype typically frames disease causation as a biological phenomenon that can be explained by, thus optimally treated through, scientific rationality. In contradistinction, the ethno-medicine aetiological ideal-type frames disease causation in relation to social phenomena - with social being inclusive of "spirits and supernatural forces" — and are thus optimally treated through "culturally sanctioned methods, herbs, incantation, and soothsaying" (Ibeneme et al. 2017, p 16). Both disease causation frames are cultural dispositions which are socially constructed perspectives people use to negotiate complex health/disease journeys (Mkhwanazi 2016). However, as with most ideal-types, realities on the ground are typically more nuanced. For example, it has been convincingly argued that in much of sub-Saharan Africa people "straddle two health-worlds simultaneously" (Moshabela et al. 2017, p 4). One example of the way in which the two ideal-types, combined with the notion of 'straddling', manifest through localized South African idioms relating to the 'origins of HIV'.

\section{Disease Causation and the 'origins of HIV' in South Africa}

In the context of HIV and AIDS in South Africa, medical pluralism is mostly associated with conspiracy theories, Christian theology, traditionalism and the biomedical perspective. The common theme within the different perspectives is particular beliefs about the legitimate 'origin of HIV' (i.e., disease causation). For conspiracy theorists, the 'origin of HIV' is associated with the belief that HIV was deliberately manufactured by whites in an attempt 
to instigate racial control over the black population - or, in extremis, racial genocide (Nattrass 2013). The Christian theology perspective is associated with the 'origin of HIV' being a punishment from God for immoral behavior (Smith et al. 2016). Traditionalism associates the 'origin of HIV' with the belief that HIV emerges from social causes (Kalichman and Simbayi 2004). The biomedical perspective takes the view that the 'origin of HIV' is best explained by the zoonotic exaptation of simian immunodeficiency viruses (SIVs) into human immunodeficiency viruses about a hundred years ago in the Congo Basin (Sharp and Hahn 2011).

From the perspective of the different sub-groups, each perspective represents a shared and coherent account of the emergence of the HIV and AIDS epidemic that is oriented to a particular belief relating to the bona fide 'origin of HIV'. Each perspective is influenced by broader systems within which the HIV narrative is nested. For example the conspiracy theorists' belief is influenced by South Africa's colonial history. Each perspective is also attributed to patterns of health seeking behaviors that manifest in self-similar ways among the group members. For example, reports relating to conspiracy theorists' account of the 'origin of HIV' indicate that this perspective of disease causation is associated with men who have sex with men who are typically situated in urban settings with a transatlantic presence who delay HIV testing and interrupt treatment (New York (USA), Heller 2015; Pretoria (South Africa), $\mathrm{Vu}$ et al. 2012). On the other hand, reports relating to traditionalism typically emerge from rural sub-Saharan African contexts with a limited trans-global presence (one rare example is Haiti, Rahill et al. 2016) who also delay HIV testing and interrupt treatment.

The sub-optimal patterns of health seeking behavior can be characterized as nonlinear feedback because the feedback (different beliefs in disease causation) produces "disproportionately major consequences" (sub-optimal health seeking behaviors) (Snowden and Boone 2007, p 70). This self-similar pattern manifests among traditionalists in parts of northern and central South Africa through, what is labeled in this article as, the HIV/makgoma conflation.

\section{The 'origins of HIV' in Northern and Central South Africa: The HIV/Makgoma Conflation}

One exemplar of how medical pluralism influences health seeking behaviours in South Africa relates to an association of HIV with a disease that traditionalists call makgoma. Makgoma is a disease that traditionalists associate with ritual defilement — which means breaking a culturally prescribed convention, or rule - that can be rectified through ritual cleansing processes prescribed by a traditional health practitioner (THP) (Shirindi and Makofane 2015). Makgoma has been reported on for at least 40 years (Mönnig 1978), but has recently become more visible in South Africa due to the convergence of makgoma with the HIV and AIDS epidemic because the symptoms of makgoma are similar to some HIV-related co-infections (Burman and Aphane 2016a). This is exemplified in a report from a popular national newspaper that cites a representative of the House of Traditional Leaders.

"Culturally, we believe that you have makgoma (dirty blood) if your lover passes away, and if you don't get proper cleansing and rituals, anyone you sleep with will get so sick, and even have the same symptoms as someone with full-blown AIDS. So it is imperative to follow the correct rituals" (Disetlhe 2014).

The similarity between the symptoms of makgoma and an HIV co-infection can produce conflicting decision making options for traditionalists which typically results in delays in testing at a biomedical facility and/or treatment interruption (Shirindi and Makofane 2015). 
There are two ideal-type representations. The first is that if the symptoms are classified using a traditionalist frame (i.e. social/ritual defilement) the culturally endorsed, normative health seeking response is to seek a consultation with a THP and enact prescribed cleansing rituals (Niehaus 2013a). The second ideal-type is that if the symptoms are classified using a biomedical frame (i.e., biological/zoonosis), the culturally endorsed, normative health seeking response is to seek biomedical advice and follow prescribed treatment regimens (typically, ART). However, returning to the notion of 'straddling', the ideal-types are — once again not the norm. There is a third scenario which is the use of both biomedical and traditional health seeking options that has been described as "therapeutic eclecticism", influenced by "local logics" which are deployed as "trial and error" health seeking strategies representing a real-world example of 'straddling' (Tariq et al. 2018, p 36).

The two ideal-types, combined with the notion of 'straddling', suggest that the 'origins of HIV' is one example of the way in which a global abstraction (disease causation) manifests through the HIV/makgoma conflation and influences treatment seeking journeys in contemporary South Africa. This represents a form of mythopraxis which has been described as the way in which "people set new events in story lines already established by their mythology .... [and the] reenactment of myth in contemporary circumstances .... [but the reenactment] never fully replicates the prototypical mythical structure" (paraphrasing Marshall Sahlins, Niehaus 2013b, pp. 652-3).

\section{Framing Medical Pluralism as a Complex Issue}

In 2007 the WHO revised their definition of a health system to a construct that "consists of all organizations, people and actions whose primary intent is to promote restore or maintain health" as part of their global commitment to health systems strengthening (emphasis added, WHO 2007, p 2). In the revised definition, the emphasis moves from 'health sector' to 'health system', with the latter positioning traditional and biomedical practitioners - as well as their patients - as interdependent components nested within broader socio-economic systems. Shortly after the revised definition was released, the WHO went a step further and defined the characteristics of health systems as "a complex adaptive system — one that self-organizes, adapts and evolves with time. The complexity arises from a system's interconnected parts, and adaptivity from its ability to communicate and change based on experience" (WHO 2009, p 40). This shift in emphasis from compartmentalized health sectors, to interdependent health systems is as relevant to medical pluralism as it is to the broader health system that it is nested within, Table 1.

The WHO's shift from health sector siloes to interconnected, complex health systems enables broader, transdisciplinary insights from complexity theorizing to be introduced into the research schema.

\section{Complex Systems}

Complex systems are comprised of agents (any internal entity that influences the system), are open to interactions with other systems and demonstrate nonlinear characteristics. Most of the time, the feedback within a nonlinear system generates linear incremental change, but sometimes the nonlinear feedback produces disproportionate consequences (Snowden and Boone 2007). The combination explains why complex systems typically demonstrate "patterns of [emergent] behaviour. .. which are never exactly repeated but are always similar to each other" (Stacey 2003, p 24) — which echoes the 'mythopraxis' observation that is referred to above. 
Table 1 The similarities between the WHO's definition of the characteristics of a complex health system and medical pluralism

(WHO 2009,pp.40-42): the WHO argue that most social systems, including health care systems are -
Examples that relate to the pluralistic health care environment in Africa
"Self-organizing: system dynamics arise spontaneously from internal structure".

"Constantly changing: systems adjust and readjust at many interactive time scales".

"Tightly linked: the high degree of connectivity means that change in one sub-system affects the others".

"Governed by feedback: a positive or negative response that may alter the intervention or its expected effects".

"Non-linear: relationships within a system cannot be arranged along a simple input-output line".

"History dependent: short-term effects of intervening may differ from long-term effect".

"Counter-intuitive: cause and effect are often distant in time and space, defying solutions that pit causes close to the effects they seek to address".

"Resistant to change - seemingly obvious solutions may fail or worsen the situation".
The different beliefs - or understandings - about the 'origins of HIV' are self-organizing phenomena.

Medical pluralism continues to adapt and change ('mythopraxis' / 'therapeutic eclecticism' based on 'local logics').

Different beliefs or understandings about disease causation influence testing and treatment.

Efforts to improve the relationships between the biomedical and traditional health sectors in sub-Saharan Africa that have sometimes made people feel 'disrespected and collaborations being short-lived' (Leclerc-Madlala et al. 2016, p 186).

Problematising disease causation has produced an increase in adherence to ART and a decrease in internalized stigma among traditionalists living with HIV (i.e., a small input produces a disproportionate output.

'Collaborations being short-lived' (Leclerc-Madlala et al. 2016, p 186).

Technically, the WHO's focus of 'history dependency' is different to the more generally accepted concept of 'initial conditions'.

Despite the South African National Department of Health $(\mathrm{NDoH})$ providing ART free, some people prefer to pay for the services of THPs to treat HIV (Audet et al. 2017).

Despite the South African NDoH providing ART free, some people prefer to pay for the services of THPs to treat HIV (Audet et al. 2017).

The consequence of the nonlinear characteristics is that attempts to "tackle them must be every bit as nonlinear" (Pacanowsky 1995, p 37). Tackling complex challenges requires moving away from change strategies that are based on mechanistic, cause-effect mind-sets (Jayasinghe 2011), towards strategies that focus on altering the attractors which represent "the core organizing principles within complex systems" (Sturmberg and Martin 2010, p 527). Identifying attractors requires retrospective analysis of the emergence in relation to the feedback between the characteristics and properties of the system at variable levels of abstraction. Recent findings in Waterberg district can be summarized from this perspective using a heuristic called the 'Iceberg Metaphor' which was developed to simplify complex system dynamics (Inayatullah 1998), Fig. 1.

During the Waterberg partnership the 'origins of HIV' represented a persistent theme that was discussed during many of the interviews. Subsequent analysis of the 'origins of HIV' suggests that (1) the characteristics of the system related to individually experienced treatment outcomes; (2) the properties related to disease causation; (3) the feedback within the system related to critical cognitive/discursive reflection about the utility of different treatment protocols (i.e., ritual cleansing and/or ART), and (4) the emergence from the system related to variable levels of HIV testing and adherence to ART (Burman and Aphane 2016a). 


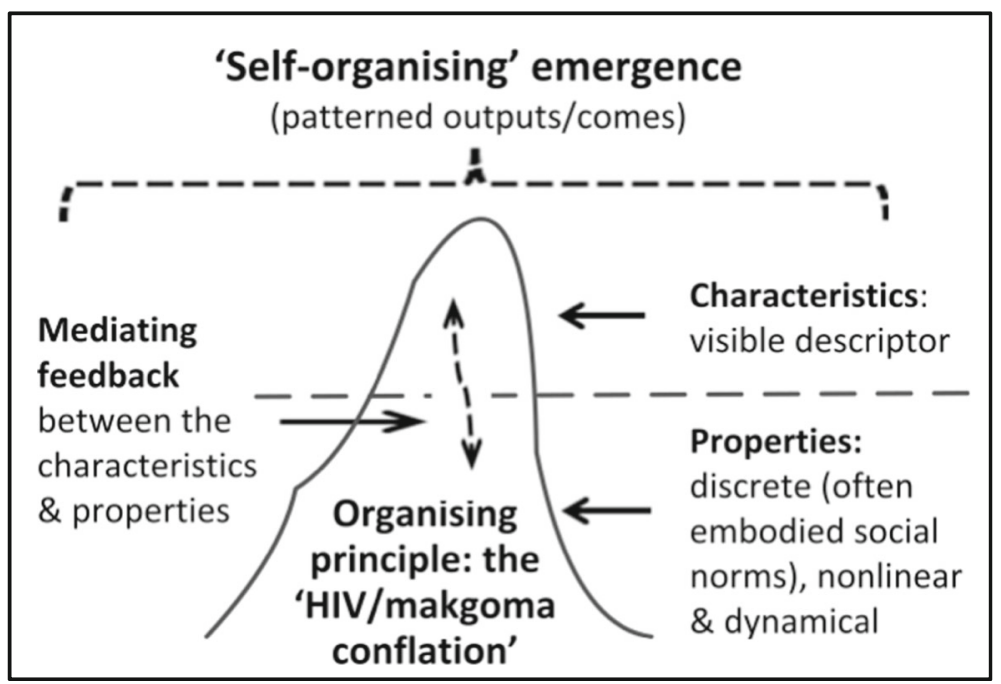

Fig. 1 The dynamics of the complex system associated with traditionalists living with HIV. Source: adapted from Burman et al. (Burman and Aphane 2016b, p 571)

Indicators in Waterberg suggest that the 'origins of HIV' represented the local narrative through which the 'core organizing principle' — the HIV/makgoma conflation — was articulated. In this example, the 'core organizing principle' was neither the characteristics nor the properties of the system. It was the feedback between the characteristics and the properties of the system which reflected indigenous perspectives that emerged from lived experiences relating to the HIV/makgoma conflation that was indirectly interconnected with the global disease causation theorem that is referred to above, Fig. 2.

From the perspective of complexity, the 'core organizing principle' at the localized, Waterberg, level was the HIV/makgoma conflation which was articulated through narrative relating to the 'origins of HIV'. From the perspective of the action-oriented research in Waterberg district, the HIV/makgoma conflation represented an opportunity for the peer educators at WWS to problematize the nonlinear dialectic between beliefs about disease causation and individually experienced health outcomes relating to the different diagnostic/

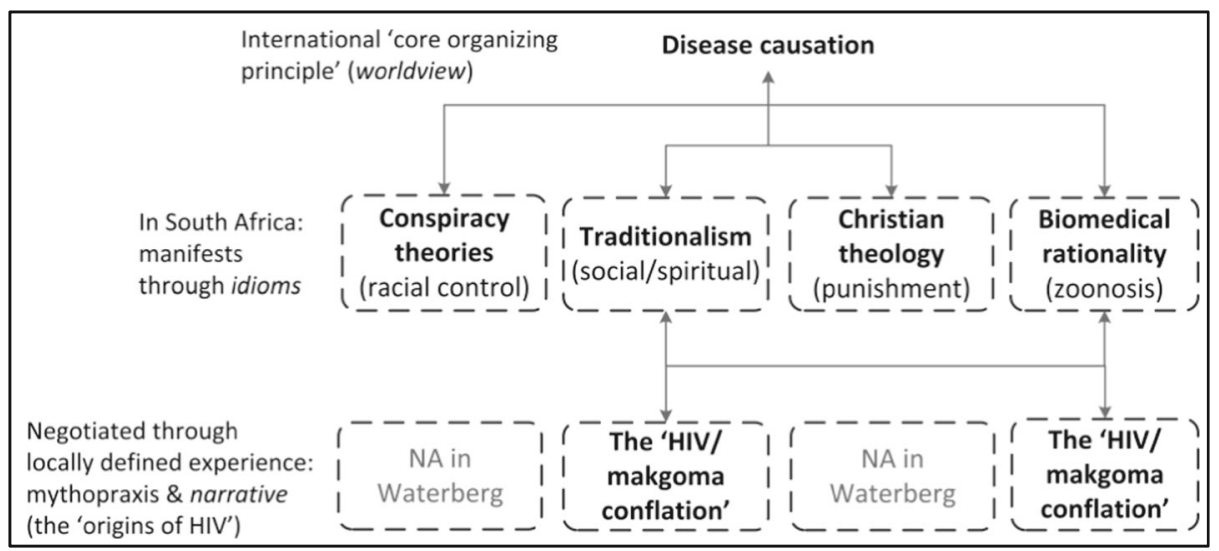

Fig. 2 The 'HIV/makgoma conflation' nested within the broader system. Source: author's contribution 
treatment journeys that people utilize as they negotiate their localized, pluralistic heath care environment. Problematizing the dialectic catalyzed, and then reinforced, treatment decision making towards a commitment to the biomedical option (Burman and Aphane 2016a). Identifying and then problematizing the nonlinear dialectic was a critical mediator of the achievements in Waterburg district and has thus been incorporated into the research schema along with other factors.

\section{Factors that Have Influenced the Development of the Research Schema}

The sections above have provided background information which indicates that (1) the patterned manifestations of the unintended consequences associated with medical pluralism (delays in testing and interruption of treatment) remain similar, despite efforts to encourage universal testing and treatment; (2) efforts to improve the collaboration between, or integration of, the 'cohabiting' health sectors in sub-Saharan Africa remain - despite the WHO's global policy shift from health sectors to health systems thinking — at an impasse, and (3) a localized intervention in Waterberg district was able to build resilience to some aspects of the 'wickedness' associated with medical pluralism using the 'origins of HIV' narrative to problematize the 'core organizing principle'.

The research schema attempts to incorporate these different perspectives in the following ways: (1) By developing a research schema that is inclusive of the interconnected agents that influence the pluralistic health care environment in order to avoid producing a linear analytical perspective that omits the nonlinear dynamics that are also likely to be discretely embedded within - and influencing - the system, and (2) identifying the narrative through which the 'core organizing principle/s' manifest, rather than focusing exclusively on the 'core organizing principle' as the primary object of research. Prior to that a statement is provided about why the research is justifiable using the influence of the HIV/makgoma conflation as an indicator.

\section{Justification for the Research Focus: The Potential Influence of Medical Pluralism}

Despite the difficulty of capturing a precise definition of either the cultural dynamics, or the influence of the HIV/makgoma conflation, it has been possible to identify the approximate geographical boundaries within which makgoma has been documented. The expression makgoma is associated with the Sotho-Tswana speaking language group (Makgahlela and Sodi 2016) and is also recognised by diverse language groups in South Africa and beyond (for example, Lesotho and parts of Botswana). In South Africa, Sotho-Tswana languages are spoken in Limpopo, North West, Gauteng and Free State Provinces and makgoma has been documented in each province (Limpopo Province, Makgahlela and Sodi 2016; Gauteng Province, Niehaus 2007; North West Province, Sebata 2015; Free State Province, Serekoane 2010). Cross referencing the provinces where Sotho-Tswana is spoken with statistics from the most recent 'South African National HIV Prevalence, Incidence and Behaviour Survey, 2012' (Shisana et al. 2014) enables an estimation of the number of people living with HIV that could be influenced by the HIV/makgoma conflation, Table 2 .

There are two factors which make the figures in Table 2 approximations. The first is that the density of Sotho-Tswana speakers within the provinces is unequal. It is also difficult to be precise about the percentage of population that is influenced by traditionalism due to the high levels of secrecy associated with reporting on traditional practices (Reid 2013). Consequently, 
Table 2 The plausible influence of the HIV/makgoma conflation on the trajectory of the South African HIV and AIDS epidemic

\begin{tabular}{|c|c|c|c|c|c|c|}
\hline Province & $\begin{array}{l}\text { HIV prevalence } \\
\text { by province, } 2012 \\
(7.2 \text { million*) }\end{array}$ & $\begin{array}{l}50 \% \\
\text { influenced by } \\
\text { traditional } \\
\text { values }\end{array}$ & $\begin{array}{l}40 \% \\
\text { influenced by } \\
\text { traditional } \\
\text { values }\end{array}$ & $\begin{array}{l}30 \% \\
\text { influenced by } \\
\text { traditional } \\
\text { values }\end{array}$ & $\begin{array}{l}20 \% \\
\text { influenced by } \\
\text { traditional } \\
\text { values }\end{array}$ & $\begin{array}{l}10 \% \\
\text { influenced by } \\
\text { traditional } \\
\text { values }\end{array}$ \\
\hline $\begin{array}{l}\text { Free State } n \\
39,920\end{array}$ & $=$ & 399,197 & 199,599 & 159,679 & 119,759 & 79,839 \\
\hline Gauteng & $1,670,814$ & 835,407 & 668,326 & 501,244 & 334,163 & 167,081 \\
\hline Limpopo & 534,947 & 267,473 & 213,979 & 160,484 & 106,989 & 53,495 \\
\hline $\begin{array}{l}\text { North } \\
\text { West }\end{array}$ & 505,650 & 252,825 & 202,260 & 151,695 & 101,130 & 50,565 \\
\hline Total & $3,110,609$ & $1,555,304$ & $1,244,244$ & 933,183 & 622,122 & 311,061 \\
\hline Free State $\%$ & 5.1 & 2.6 & 2.0 & 1.5 & 1.0 & 0.5 \\
\hline Gauteng & 24.1 & 12.1 & 9.6 & 7.2 & 4.8 & 2.4 \\
\hline Limpopo & 10.4 & 5.2 & 4.2 & 3.1 & 2.1 & 1.0 \\
\hline $\begin{array}{l}\text { North } \\
\text { West }\end{array}$ & 6.8 & 3.4 & 2.7 & 2.0 & 1.4 & 0.7 \\
\hline Total & 46.4 & 23.2 & 18.6 & 13.9 & 9.3 & 4.6 \\
\hline
\end{tabular}

*The South African National HIV Prevalence, Incidence and Behaviour Survey, 2012 estimated that the national HIV prevalence rate in South Africa was 7.2 million (Shisana et al. 2014)

five scenarios relating to the percentage of population living with HIV who may be influenced by the HIV/makgoma conflation within the Sotho-Tswana language area, ranging from $50 \%$ $10 \%$, have been provided.

The figures in Table 2 suggest that of the total number of people known to be living with HIV in South Africa between 23\% (about 1.5 million people if the $50 \%$ influence indicator is applied) and almost 5\% (about 300,000 people if the $10 \%$ indicator is applied) could be influenced by the HIV/makgoma conflation. By default, this suggests they could have delayed testing, might be interrupting treatment and the de facto likelihood is that these figures omit people who are currently undiagnosed which has been estimated to be as high as $18.9 \%$ in one hyper-endemic community (Vandormael et al. 2018).

The combination of traditionalists living with HIV, and the undiagnosed possibles, represents a low-visibility cohort of people at risk due to one manifestation of medical pluralism that is labelled as the HIV/makgoma conflation. It should also be noted that the HIV/makgoma conflation is only one manifestation of medical pluralism in South Africa. It is likely that there are other locally defined manifestations relating to HIV in other parts of the country which could increase the numbers of affected people. Based on the estimations in Table 2, the likelihood that there are other locally manifestations and the possibility that there may be similar patterns affecting people living with non-communicable diseases it was decided that the research focus is legitimate.

\section{Complexity and Medical Pluralism: Framing the Research Schema Systemically}

Medical pluralism is well researched, manifests in variable ways, is dynamic and is one of many co-factors that influences linking and retaining people living with HIV in biomedical care (Flores et al. 2016). There have also been multiple reports that indicate that the influence of medical pluralism produces 'disproportionately major' unintended consequences (delays in testing and 
interruption of treatment). This has epistemological implications relating to the suggestion, above, that medical pluralism has the characteristics of a nonlinear system which is nested within a broader complex system (Fig. 2). From an action-oriented research perspective it is thus necessary to incorporate the nonlinear influences within the system into the research schema - rather than develop an analysis that isolates medical pluralism from the broader context.

\section{Framing Medical Pluralism as a Complex Challenge}

In the sections above causality is barely mentioned. This is because the HIV/makgoma conflation is an influential component within a nonlinear system comprised of a mosaic of interdependent co-factors that influences health seeking decision making. This is not to say there is no causality at play, but it is to say that this research schema is designed on the basis that the pluralistic health care environment in South Africa contains sufficient nonlinearity to frame it as a complex social phenomenon. The consequences are that the research schema was designed to identify and respond to the narratives associated with the 'core organizing principles' within the system as a mechanism to build resilience to the unintended consequences associated with medical pluralism.

\section{The 'core organizing principles', Attractors and the Research Schema}

Strictly speaking, attractors, or 'core organizing principles' are defining characteristics that enable differentiation between system typologies (Pascale et al. 2000). However, from the perspective of designing an action-oriented research schema, reflections from the earlier work in Waterberg was influential. The Waterberg experience indicated that the essential component of relevance in the action-oriented research was not the attractors, or the 'core organizing principles', within the system of interest. The essential action-oriented research component was the narrative through which the attractors, or the 'core organizing principles', manifest because the narrative enabled critical cognitive/discursive reflection about the dialectic/s within particular treatment seeking journeys and subsequent health-related outcomes that are experienced at both an individual and social level of granularity. It is believed that reaching those variable levels of granularity can be achieved by adopting perspectives associated with the Mauri Model decision making framework using an analytical method associated with critical realism called 'AART'.

\section{Framing the Research Schema through Indigenous Decision Making: The Mauri Model Decision Making Framework}

In order to reach the variable levels of granularity that influenced the Waterberg experience, the Mauri Model decision making framework perspective has been adopted. The Mauri Model decision making framework is designed to provide a "template within which indigenous values are explicitly empowered alongside scientific data" (emphasis added, Morgan and Fa'aui 2017, p 4). The word mauri is a Māori expression that refers to 'life force', or an aura that supports a form of life. The Mauri Model decision making framework represents the process through which an indigenous concept became officially endorsed as a goal within a government-led strategy to mitigate the impact of a national environmental disaster (Faaui et al. 2017). The negotiated process represents a first in New Zealand's history and the concept has subsequently been re-used in other action-oriented projects (for one example relating to chronic disease mitigation, see Oetzel et al. 2017). 
What makes the Mauri Model decision making framework relevant to the research schema is that in New Zealand approximately $17.5 \%$ of the population are of Māori dissent (Statistics New Zealand 2013) - and they represent a historically marginalized group. Nevertheless, the New Zealand government endorsed the Māori request that their values and beliefs become integrated into the environmental disaster mitigation plan. In contradistinction, in rural South Africa the majority of the population are indigenous and yet the formal health system tends to be both framed and operationalized through a biomedical lens which has led to reports that sometimes traditionalists feel "disrespected" (Leclerc-Madlala et al. 2016, p 286). It is anticipated that adopting the principles of the Mauri Model decision making framework will enable "the development of more nuanced, context-sensitive" insights into the pluralistic health care environment within the study area (Hernandez et al. 2017, p 5) that avoids "othering those central to the story" (Mkhwanazi 2016, p 7).

\section{Analytical Frame of the Research Schema: Critical Realism and 'AART'}

Critical realism is a sub-domain of philosophy of science that is recognised for the epistemological contributions it has made to the social sciences. Recently, ethnographic critical realism has been used to contribute to literature relating to HIV and medical pluralism by Decoteau (2017). In 2005, Decoteau reported on seemingly contradictory qualitative ethnographic findings relating to medical pluralism in South Africa. In order to find coherence within the seemingly contradictory findings she convincingly re-analyzed them using a method that she labelled "AART (abduction, abstraction, retroduction, testing)" (Decoteau 2017, p 58).

For Decoteau the first step in the method - 'abduction' - is to re-contextualize the object/ $\mathrm{s}$ of the research and then ask how the object/s of research interact with associated structures and social relations as a mechanism to generate new ideas which enables "hypothesisgeneration for innovative theorizing" (Decoteau 2017, p 72). From this basis she argues that the next step is 'abstraction' which involves using the empirical findings to consider new theoretical perspectives about the relationships that connect the object/s of research to the entities identified in the 'abduction' phase. The third step - 'retroduction' — involves building a model, or models, that can explain how the emergent abstraction would actually work in practice. After the modelling, Decoteau argues that rigorous 'testing' of the model the ' $\mathrm{T}$ ' in 'AART' - is required to determine its utility in real-world settings. Due to the synergies between the potentials of Decoteau's method and the ambition of the action-oriented research schema it was decided that the 'AART' model would be co-opted. In order to catalyze the first 'A' ('abduction) in 'AART' from the perspective of indigenous decision making and health seeking behavior required an innovative design. It was subsequently decided that proprietary software called SenseMaker ${ }^{\circledR}$ would be incorporated into abductive phase of the project.

\section{SenseMaker ${ }^{\circledR}$}

SenseMaker® is a browser-based software program licensed by Cognitive Edge that provides opportunities for rapid online mixed method data collection and real-time data analysis/ retrieval (UNDP 2013). Reports relating to the use of SenseMaker® in peer reviewed journals are limited, but include applications in the contexts of child refugees in Syria (Bakhache et al. 2017); gender relations (DFID 2014) and climate change (Lynam and Fletcher 2015). 
SenseMaker® enables analyses of respondents' stories, by provisioning the end-user with both a data collection template and a suite of data analysis tools (Lynam and Fletcher 2015). The underlying logic of the data collection tool is that people tell stories, but the particular meaning that is attributed to that story, by the story-teller, is embodied within interdependencies between both the story-teller and context. The implication is that the optimal mechanism to gain insights into the embodied meaning of the story is to have the respondents (the story-tellers) self-code the stories, rather than have an expert code it on their behalf (Mausch et al. 2018). The selfcoding capability that SenseMaker ${ }^{\circledR}$ provides represents a form of disintermediation which reduces researcher bias during the data collection phase (Bartels et al. 2018).

The underlying logic of the data analyses component of SenseMaker® is to convert the qualitative associations represented within the self-coding into quantitative data. This enables visual patterns of the qualitative data to be examined using the different quantitative functions, as well as to generate some purely quantitative outputs. This enables the end-user to examine the narrative data from a mixed methods perspective at multiple levels of granularity (Casella et al. 2014).

\section{Why SenseMaker ${ }^{\circledR}$ ?}

This application of SenseMaker® has been enabled through a partnership with the Cynefin Centre, University of Bangor. The Cynefin Centre is currently engaged in a global project called the Making of Meaning which focuses on how people are making contemporary meaning in a changing world (The Cynefin Centre 2018). The decision to use SenseMaker ${ }^{\circledR}$ was prompted by (1) the potentials that the self-coding capability could provide for generating insights into indigenous decision making to be 'empowered alongside scientific data', and (2) the potential of the findings to stimulate the first 'A' (abduction) in 'AART'.

\section{The Sensemaker ${ }^{\circledR}$ Instrument}

For optimal outputs a SenseMaker® instrument requires being designed from both a social and individual perspective. The social perspective enables the end-user to examine the results using aggregated visualizations of the findings and the individualistic perspective enables deep dives into particular aspects of disaggregated findings. Typically, a SenseMaker® instrument should aim for about 300 responses per study area to facilitate the movement across different levels of granularity during the analysis phase (Bakhache et al. 2017).

The SenseMaker ${ }^{\circledR}$ instrument that will be applied includes five components: (1) a story prompt; (2) a series of signifiers, including (2.1) six triads which the respondents use to selfcode, thus contextualize, their story, (2.2) six dyads along which the respondents are asked to situate (self-code) their stories; (3) a series of multiple choice questions; (4) a change story for those people who have switched from using a THP to an biomedical health practitioner, or vice-versa, and (5) respondent demographics, Table 3.

The signifiers that have been developed for this SenseMaker® instrument include triads and dyads. Prior to explaining how the signifiers were designed, the use of the signifiers is explained for the sake of clarity.

\section{Using Triads and Dyads}

Each corner of a triad represents a variable, or co-factor, which could influence the issue under investigation. For example, if the story prompt were a request for a story that happened in the 
Table 3 An overview of the SenseMaker® instrument that is presented to respondents

The components of the instrument Details

(1) Story prompt (story requested from the respondent)

(2.1) Triads (self-coded by respondent)*

(2.2) Dyads (self-coded by respondent)*

(3) Multiple choice questions (self-coded by respondent)*

(4) Change stories (story volunteered by the respondent)*

(5) Respondent demographics*
One story is requested from each respondent. The current prompting question that may be adapted after piloting/translating is:

'Sometimes when people feel a need to consult a health practitioner they consider different options. Some go to traditional healers, some seek spiritual healing, others go to clinics / hospitals and some use a combination of these options. Can you think of a time when you faced such a decision? What happened? Describe it in a few sentences'.

The story prompt is deliberately open ended, allows the respondent to decide which story is relevant to them and does not mention the focus of the research (medical pluralism) in order to reduce social desirability bias (Bakhache et al. 2017).

The triads enable the respondents to situate their story within a particular context (self-coding). This means that the first round of coding is undertaken by the respondent - not an expert intermediary. This disintermediation enables dispositional indigenous values to be situated within both everyday wisdom and scientific data by the respondent.

Dyads are used to test perceived and/or taken for granted wisdoms. Respondents also situate their story within the dyad (self-coding).

The multiple choice questions are the same as a standard survey. They are linked to the triads and dyads by the software and used as filters during the analysis phase. The purpose of the electronic linkage is to analyze particular patterns (for example gender, age, employments status etc.) relating to the relationships between the triads and/or dyads at multiple levels of granularity.

Literature indicates that some people who begin the journey from pre-decision making through to subsequent health seeking behaviours start in the traditional health sector then commit to biomedical treatment. This means that people may have experiences of what influenced them to make the change. In the genre of the 'Most Significant Change' technique (Dart 2003), it is hoped that insights about the change process will emerge.

Demographics are standardized and have followed the same categories that were applied in the most recent South African National HIV Prevalence, Incidence and Behaviour Survey, 2012 (Shisana et al. 2014).

*All have a 'NA' option

last 3 days, the respondent would then be asked to situate (self-code) their story within a series of triads. This provides the story-teller with an opportunity to contextualize their story by situating it relative to each of the three co-factors, or variables, in each triad. One example of a triad relating to the above prompt — the 'last 3 days' — is provided below, Fig. 3.

To self-code the story within either a triad or dyad the respondent moves the ball in the center of the triad or dyad to the position that most reflects their contextualized response. In the example above, Fig. 3, if the respondent's last 3 days had included a public holiday and weekend, they might situate their story somewhere between 'Relaxing' and 'Sleeping'. However, if they had an overdue deadline to complete, they might move the ball somewhere closer to 'Sleeping' and 'Working'. A similar approach is used to self-code the story along a dyad which is designed using the principles of Aristotle's golden mean — with one polarity of the dyad reflecting a scale of excess and the other polarity, a scale of deficiency, Fig. 4. 


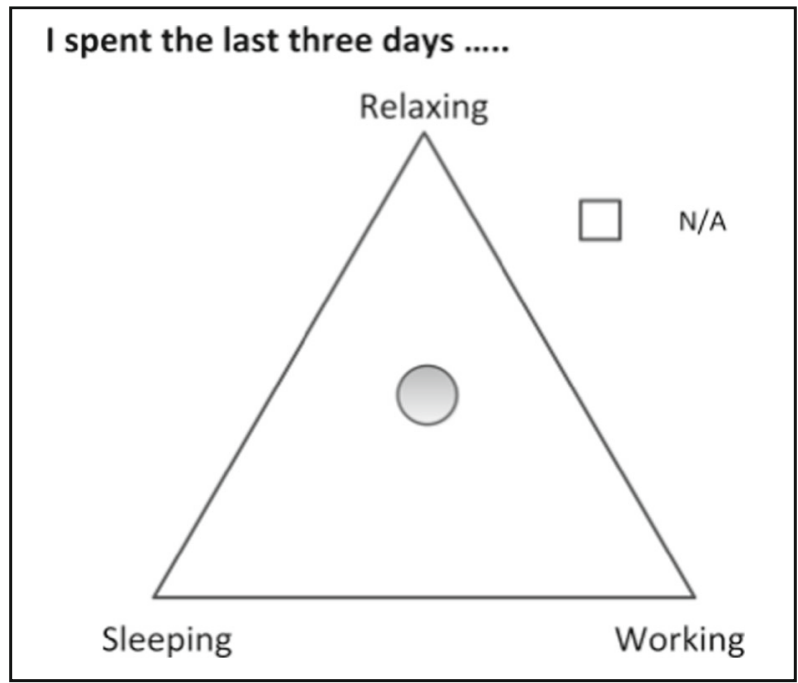

Fig. 3. A triad: the ball in the center is placed in the most appropriate position within the triad by the respondent (i.e., self-coded).

In this instance, the ball is placed closest to the position that represents their interpretation of their last 3 days. For optimal benefit to be exploited from the triads and dyads they need to be rigorously designed and piloted. In this instance, both the triads and dyads were designed using a polymorphic technique.

\section{Designing the Data Collection Instrument}

The design process was iterative and included the following phases: (1) receipt of a polymorphic signifier design template that included some triads by the Cynefin Centre, University of Bangor; (2) development of a draft signifier set — both triads and dyads - that was aligned with the polymorphic template; (3) a 2 day workshop with academics from the Universities of Witwatersrand and KwaZulu-Natal, the Human Sciences Research Council and community based experts facilitated by a signifier design expert from More Beyond to design a new set of polymorphic triads and dyads; (4) the development of a new signifier set based on the 2 day dialogue which was partially combined with the earlier version, and (5) a pilot, followed by further modification.

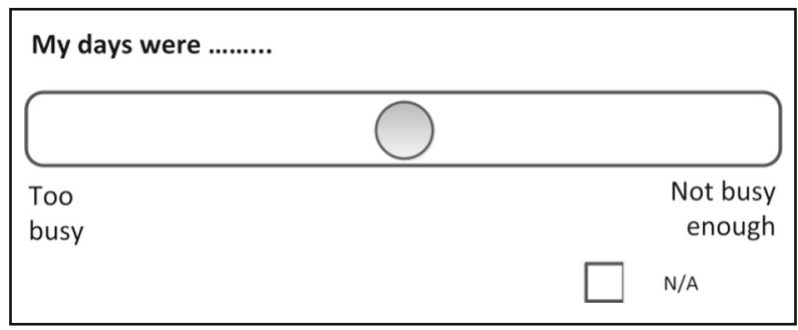

Fig. 4. A dyad: the ball in the center is placed at the most appropriate position along the continuum by the respondent (i.e., self-coded). 


\section{Designing Polymorphic Signifiers}

When an end-user designs a SenseMaker® instrument they begin with an empty signifier template which they populate depending on the focus of their study. In the context of the Making of Meaning project, the local partners are provided with a set of polymorphic triads which relate to the focus of the global project. The partners are then asked to use some of the polymorphic triads and re-purpose them to meet their local needs. The first draft signifier set was influenced by a global meta-synthesis of factors that influence linkage and retention in HIV care (Flores et al. 2016). The meta-synthesis identifies three dominant streams that influence linkage and retention in HIV care - intra-personal, social and cultural/attitudinal — which are all populated by multiple sub-themes. For full details see Supplementary Material, Table A.

During the 2 day signifier design workshop the first draft was not shared with the participants. The participants were asked to use their intuitive expertise to design a new polymorphic template. During the discussions that took place it was suggested that the findings of 'The determinants of traditional medicine use in Northern Tanzania: a mixed-methods study' (Stanifer et al. 2015) could influence the design process. This was an extremely relevant contribution which enabled the focus on both communicable and non-communicable diseases to be included into the research schema because the first draft had unintentionally become exclusively focused on linkage and retention in HIV care, despite the project focus on medical pluralism.

The addition that this suggestion brought to the design process was determinants that influence the use of traditional medicine including: (1) the credibility of traditional practices; (2) the health status of an individual; (3) disease understanding, and (4) the quality of biomedical health care delivery (or full details see Supplementary Material, Table B). Despite the study being done in Tanzania, the findings are based on empirical evidence, have similarities with findings from South Africa and were sufficiently succinct to be absorbed into the polymorphic design.

\section{Triads}

The combination of influences has resulted in six polymorphic triads all of which have three analytical levels that can be used during the analysis, Fig. 5 .

Compressing so many analytical potentials into conventional mixed method data collection instruments is unusual. However, the polymorphic design enables this because the respondent is only presented with one triad, but the underlying layers can be analyzed from multiple perspectives at varying levels of abstraction. The perspectives that influence decision making include Level 1: linkage and retention in HIV care (Flores et al. 2016); Level 2: the determinants of traditional medicine utilization (Stanifer et al. 2015), and Level 3, indigenous values and beliefs (The Cynefin Centre 2018). This combination dovetails with the ambition of the Mauri Model decision making framework to 'empower indigenous decision making alongside scientific data'. One triad — the 'knowledge triad' — is presented to explain in more detail, Fig. 6 and Table 4.

The polymorphic approach enables the following potential levels of analysis relating to 'knowledge' to be re-interrogated, Table 4. 


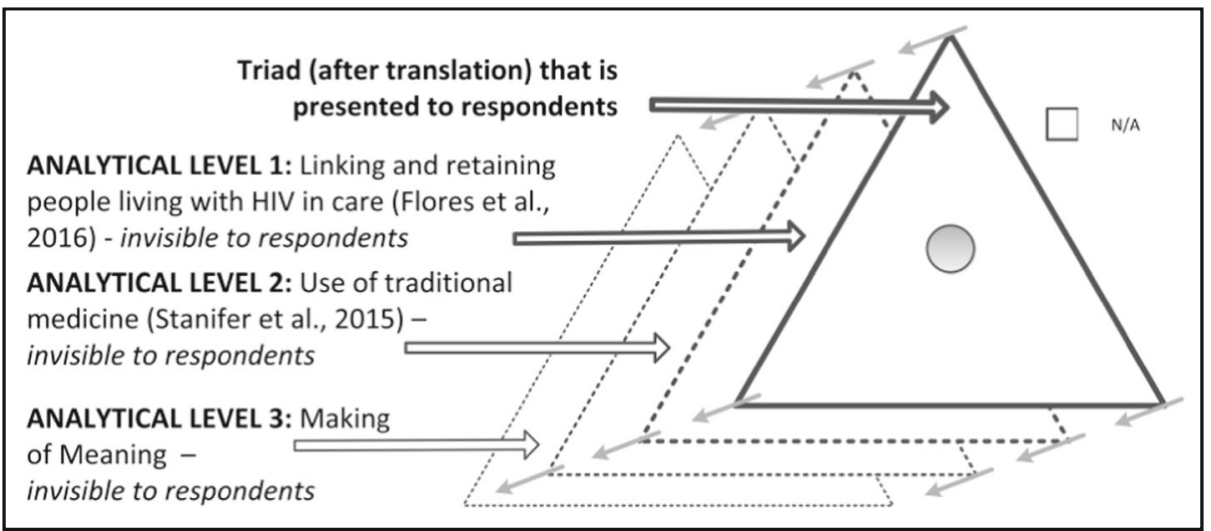

Fig. 5 The polymorphic, multi-level analyses triad design

The links to the three levels of analyses are not perfect fits. However, the links represent a start point for the 'AART' analysis. For the six triads and associated levels of analyses see Supplementary Material, Table C.

\section{Dyads}

The purpose of the dyads is to test general assumptions associated with medical pluralism and health outcomes from the perspective of indigenous decision makers. For example, one dyad is designed to test the hypothesis that disease causation influences health seeking decision making, Fig. 7.

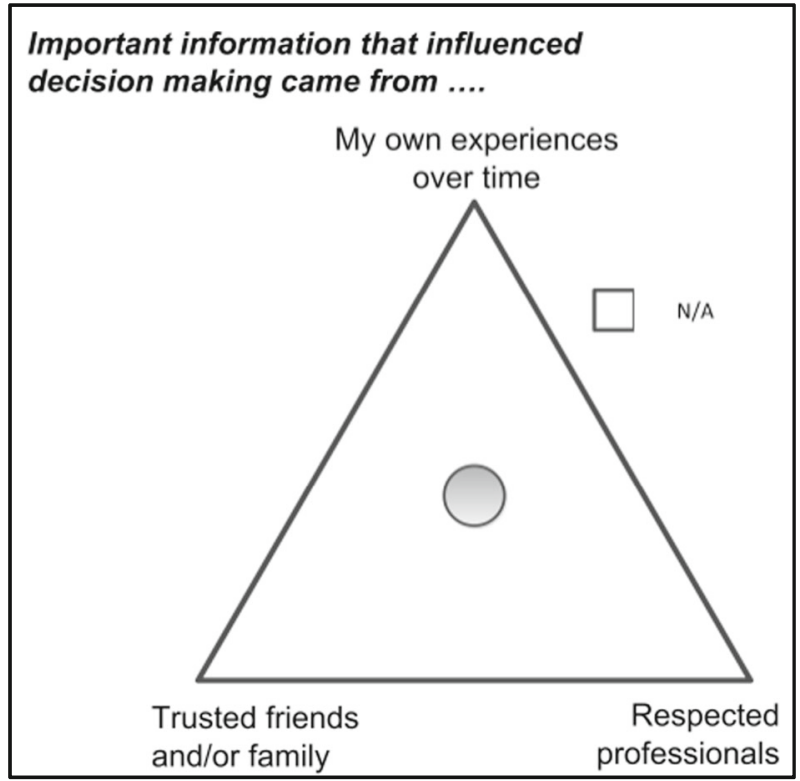

Fig. 6 The polymorphic 'knowledge triad' that will presented to the respondents 
Table 4 The multiple analytical levels contained within the 'knowledge triad'

\begin{tabular}{|c|c|c|c|c|c|}
\hline $\begin{array}{l}\text { Theme of } \\
\text { the triad }\end{array}$ & Triad prompt & $\begin{array}{l}\text { Visible triad } \\
\text { label } \\
\text { presented to } \\
\text { the } \\
\text { respondents }\end{array}$ & $\begin{array}{l}\text { Level 1: Linkage } \\
\text { and retention in } \\
\text { HIV care (Flores } \\
\text { et al. 2016)* }\end{array}$ & $\begin{array}{l}\text { Level 2: Traditional } \\
\text { medicine use } \\
\text { (Stanifer et al. } \\
\text { 2015)** }\end{array}$ & $\begin{array}{l}\text { Level 3: the } \\
\text { Cynefin } \\
\text { Centre's } \\
\text { template*** }\end{array}$ \\
\hline $\begin{array}{l}\text { Influential } \\
\text { knowl- } \\
\text { edge } \\
\text { sources }\end{array}$ & $\begin{array}{l}\text { Important } \\
\text { information that } \\
\text { influenced } \\
\text { decision making } \\
\text { came from... }\end{array}$ & $\begin{array}{l}\text { - My own } \\
\text { experiences } \\
\text { over time } \\
\text { - Trusted } \\
\text { friends and } \\
\text { / or family } \\
\text { - Respected } \\
\text { profes- } \\
\text { sionals }\end{array}$ & $\begin{array}{c}\text { - Informational } \\
\text { challenges }\end{array}$ & $\begin{array}{l}\text { - Disease } \\
\text { understanding } \\
\text { - Strong cultural } \\
\text { identities } \\
\text { - Credibility of } \\
\text { traditional } \\
\text { practices / bio- } \\
\text { medical } \\
\text { healthcare deliv- } \\
\text { ery }\end{array}$ & $\begin{array}{l}\text { - Emergent } \\
\text { knowl- } \\
\text { edge } \\
\text { - Distributed } \\
\text { knowl- } \\
\text { edge } \\
\text { - Routine } \\
\text { knowl- } \\
\text { edge }\end{array}$ \\
\hline
\end{tabular}

*See Supplementary Material, Table A for full details of the potential scope that can be used to analyze the findings

**See Supplementary Material, Table B for full details of the potential scope that can be used to analyze the findings

*** There is a sizeable body of material relating to 'knowledge' that can be used to analyze the different knowledge typologies that are referred to.

The purpose of this dyad is to validate whether the literature relating to disease causation and the findings from the Waterberg experience are reflected in the self-coded opinions of the respondents. Dyads do not offer the potential depth of analysis that the triads do, but may assist to draw boundaries around the concepts that are relevant during the subsequent analysis. See Supplementary Material, Table D, for the six dyads.

\section{Data Analysis}

The start point of the analysis will begin with observing screen shots of the distributions of clustered patterns that represent the aggregation of the individual stories within each triad and then to begin analyzing the patterns at different levels of granularity using the multiple choice responses as filters. An imagined scenario is played out below, Fig. 8.

\section{The cause/origins of the symptoms influenced decision making in your story .........}

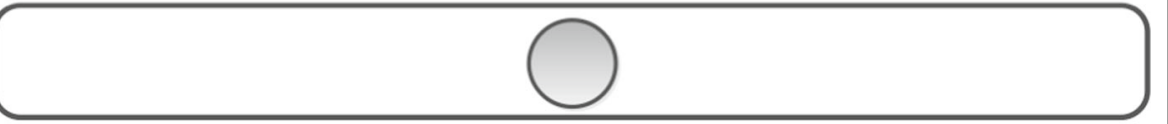

\section{Significantly} (the 'excess' polarity)

Fig. 7 The 'knowledge dyad' that will presented to the respondents 


\section{Screen shot 1}

\section{Important information that influenced decision making came from ....}

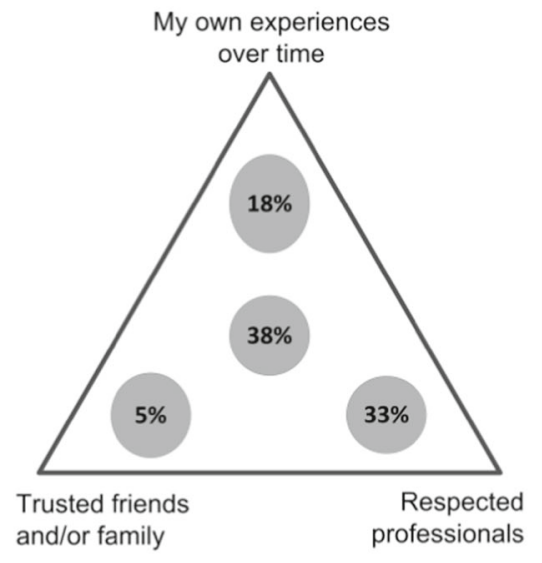

\section{Screen shot 2}

\section{Important information that influenced decision making came from ....}

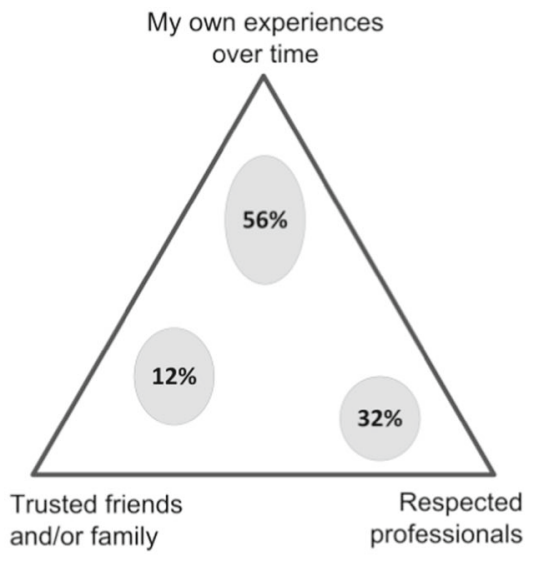

Fig. 8 An imagined data set of total responses for female and male cohorts

The patterns of the total response are the start point. In this imagined example, similar amounts of women and men have situated (self-coded) their story close to the 'Respected professionals' label. However, the type of professional is not known. In the SenseMaker® instrument, one multiple choice question asks the respondents which type/s of health practitioner they were consulting with (i.e., traditional or biomedical health practitioner, or a combination of both). The software enables the female/male clusters, Fig. 8, to be disaggregated into any of the three health practitioner/ consultation response options. This can then be further disaggregated using other variables, such as age or employment status etc.

Once the level of granularity under re-interrogation is established it is then possible to analyze individual stories within the particular sub-clusters because they are also electronically linked to the sub-cluster that remains on the screen. Analyzing the individual stories - another level of granularity - provides insights into the characteristics of the particular sub-cluster. Analysis of the stories in the sub-cluster may also provide insights into the properties of the system. However, it may be necessary to identify a representative sample from within the original sample and request key informant interviews to clarify issues to augment the original story in order to gain insights into the feedback between the properties and the characteristics of that particular sub-cluster.

This analytical technique holds potentials to provide a qualitative re-interrogation of the complex system under analysis from the perspective of indigenous decision makers in 'relation to scientific data'. The qualitative re-interrogation can be augmented using the quantitative functions of SenseMaker® - including correlations, $t$ tests and three dimensional modelling (Lynam and Fletcher 2015) and more in depth analysis has been reported on using a combination of Tableau V.10.1.5, SPSS (IBM 
SPSS Statistics V.24.0.0.0) and R scripts (R V.3.4.0) (Bartels et al. 2018). The combination of qualitative and quantitative insights generates momentum for the subsequent phases of the 'AART' method because the first 'A' (abduction) has been initiated in the steps outlined above.

\section{Other Research Considerations}

For the sake of brevity, the planned implementation details are summarized below. Some of these details may be subject to change due to the exploratory nature of the pilot, Table 5 .

It is not expected that the implementation phases of the research will require any special preparation - with the exception of training relating to the use of the triads and dyads.

\section{Anticipated Limitations}

At this stage it is difficult to predict the limitations. One consideration includes the limited battery life of electronic devices used for data collection and network coverage in deep rural areas. Another anticipated challenge is that traditional medicine use is typically associated with secrecy (Reid 2013), thus respondents may be unwilling to volunteer related experiences. Secondary literature also indicates that the statistical functionality of SenseMaker® is weak (Lynam and Fletcher 2015), but exporting the data for quantitative analysis should reduce this reported caveat. Nevertheless, the research schema is considered to be a pilot so all weaknesses and limitations will be documented.

Table 5 Summary of technical research details

\begin{tabular}{|c|c|}
\hline $\begin{array}{l}\text { Protocol } \\
\text { requirement }\end{array}$ & Comment \\
\hline Sampling & $\begin{array}{l}\text { Purposive / snowballing. (1) Adults living with a chronic disease will be targeted (HIV, } \\
\text { TB, diabetes and hypertension) and (2) People affected by a chronic disease who may } \\
\text { have insights to offer (e.g., community health workers, peer educators, nurses, family } \\
\text { members). The focus has shifted away from an exclusive focus on HIV due to the } \\
\text { multiple choice functionality in SenseMaker®. In practice this means that there will be } \\
\text { one multiple choice question asking which chronic disease the respondent is living with } \\
\text { and this will then enable analyses of any combination of the diseases reported on. }\end{array}$ \\
\hline Study sites & $\begin{array}{l}\text { Waterberg district, Limpopo Province (rural); the Dikgale Health and Demographic } \\
\text { Surveillance System (HDSS) site, Capricorn district, Limpopo Province (rural); a study } \\
\text { site to be selected by the Africa Health Research Institute, KwaZulu-Natal Province } \\
\text { (rural); a study site to be selected by the Centre for Learning and Evaluation on } \\
\text { Research, University of Witwatersrand (urban). }\end{array}$ \\
\hline $\begin{array}{l}\text { Training of field } \\
\text { workers }\end{array}$ & $\begin{array}{l}\text { Training will include a minimum } 2 \text { day workshop to explain the rationale of the instrument } \\
\text { and the data collection requirements. }\end{array}$ \\
\hline Data collection & $\begin{array}{l}\text { A combination of IPads and laptop computers will be used to collect data. Paper data } \\
\text { collection will be used as a last resort. All normal ethical protocols will be applied } \\
\text { throughout. }\end{array}$ \\
\hline $\begin{array}{l}\text { Facilitation of } \\
\text { research }\end{array}$ & $\begin{array}{l}\text { Each study site will be assigned a team leader to troubleshoot using appropriate support } \\
\text { measures. Four trained facilitators will collect data in each site over a } 2 \text { month period. }\end{array}$ \\
\hline
\end{tabular}




\section{Concluding Comments}

In the context of the HIV and AIDS epidemic in sub-Saharan Africa the most prevalent unintended consequences associated with medical pluralism are delays in testing and treatment interruption. There is also a consensus that the optimal way to reduce the unintended consequences is to improve the structural relationship/s between the 'cohabiting' health sectors. The WHO have committed to a shift from mechanistic health sector thinking, to an interconnected systems paradigm. This commitment provides a timely opportunity - invigorated by the findings in Waterberg district, Limpopo Province - to re-interrogate the pluralistic health care environment in study sites in three South African provinces. The re-interrogation will include the agency of the clients (the patients) within the health system as intentional actors who could contribute to reducing the unintended consequences, irrespective of the structural relationship/s between the 'cohabiting' health sectors. This represents a methodological shift from using 'structure' as a systemic referential axis of enquiry (the norm, in the context of medical pluralism) to using the agency of indigenous decision makers as an alternative, exploratory referential axis of enquiry.

The research schema that has been presented aims to achieve this in the following way. First, the research schema frames the pluralistic health care environment in South Africa as a nonlinear system comprised of interconnected health practitioners, patients and other influential agents. Second, acknowledging that there have been very few, if any, attempts to frame the pluralistic health care environment in South Africa from the perspective of nonlinear complexity, it is pragmatic to begin with an 'abductive' focus (the first 'A' in the 'AART' model). Third, in order to avoid the potential caveats within the linear preference for using 'structure' as a systemic referential axis of enquiry, the research schema is framed through the perspectives of both indigenous decision making and scientific data (the Mauri Model decision making framework), whilst being cognizant of the importance of 'core organizing principles' and associated narratives (such as the 'origins of HIV'). From this foundation novel opportunities may emerge that can be directly applied by grassroots actors (the patients) which could, indirectly, influence the health practitioners and other relevant social actors (family, friends, trusted confidants and community) with whom they interact ('testing' in 'AART'). Fourth, due to the exploratory nature of the research schema, a significant amount of effort will focus on critically reviewing the research process to ensure that lessons learnt are properly recorded because the schema may have potentials to be applied in other contexts.

From this basis, it may be possible to build resilience — in the form of emergent, novel social practices - that could contribute to reducing the unintended consequences (delays in testing and treatment interruption) of the 'wickedness' associated with medical pluralism in parts of South Africa and - possibly — beyond. However, only empirical evidence from the forthcoming pilot can validate these theoretical claims.

Acknowledgements The development of the research schema has emerged from earlier action-oriented research funded by the National Research Foundation. It work was also made possible thanks to the cooperation of the Waterberg Welfare Society (WWS). I would also like to extend my appreciation to the Cynefin Centre, University of Bangor and colleagues that joined the 2 day signifier design workshop in September, 2017, including representatives from the Universities of Witwatersrand and KwaZulu-Natal, the Human Sciences Research Council, The Business Coalition on AIDS and Health (SABCOHA) and More Beyond. Any opinion, finding and conclusion or recommendation expressed in this material is that of the author; the NRF, WWS and the institutions cited above do not accept any liability in this regard.

\section{Compliance with Ethical Standards}

Conflict of Interest The author declares that the research was conducted in the absence of any commercial or financial relationships that could be construed as a potential conflict of interest. 
Open Access This article is distributed under the terms of the Creative Commons Attribution 4.0 International License (http://creativecommons.org/licenses/by/4.0/), which permits unrestricted use, distribution, and reproduction in any medium, provided you give appropriate credit to the original author(s) and the source, provide a link to the Creative Commons license, and indicate if changes were made.

\section{References}

Ahern J (2011) From fail-safe to safe-to-fail: sustainability and resilience in the new urban world. Landsc Urban Plan 100(4):341-343. https://doi.org/10.1016/j.landurbplan.2011.02.021

Audet CM, Ngobeni S, Wagner RG (2017) Traditional healer treatment of HIV persists in the era of ART: a mixed methods study from rural South Africa. BMC Complement Altern Med 17(1):434. https://oi. org/10.1186/s12906-017-1934-6

Bakhache N, Michael S, Roupetz S, Garbern S, Bergquist H, Davison C, Bartels S (2017) Implementation of a SenseMaker(R) research project among Syrian refugees in Lebanon. Glob Health Action 10(1):1362792. https://doi.org/10.1080/16549716.2017.1362792

Bartels SA, Michael S, Roupetz S, Garbern S, Kilzar L, Bergquist H, Bakhache N, Davison C, Bunting A (2018) Making sense of child, early and forced marriage among Syrian refugee girls: a mixed methods study in Lebanon. 3 In: BMJ Global Health, vol 1. pp 1-13. https://doi.org/10.1136/bmjgh-2017-000509

Brown VA, Harris J, Russell J (eds) (2010) Tackling wicked problems: through the transdisciplinary imagination. Earthscan, London

Burman CJ, Aphane M (2016a) Community viral load management: can 'attractors' contribute to developing an improved bio-social response to HIV risk-reduction? Nonlinear Dynamics Psychol Life Sci 20(1):81-116

Burman CJ, Aphane M (2016b) Complex adaptive HIV/AIDS risk reduction: plausible implications from findings in Limpopo Province, South Africa. S Afr Med J 106(6):571-574. https://doi.org/10.7196 /SAMJ.2016.v106i6.10255

Burman CJ, Aphane M (2017) Complex HIV/AIDS landscapes: reflections on how 'path creation' influenced an action-oriented intervention. Syst Pract Action Res 30(1):45-66. https://doi.org/10.1007/s11213-016-9385-4

Casella D, Magara P, Kumasi TC, Guijt I, van Soest A (2014) The Triple-S Project Sensemaker® experience: a method tested and rejected. International Water and Sanitation Centre, The Hague. https://www.ircwash.org/resources/triples-project-sensemaker\%C2\%AE-experience-method-tested-and-rejected. Accessed 18 December, 2017

Dart J (2003) A dialogical, story-based evaluation tool: the most significant change technique. Am J Eval 24(2): 137-155. https://doi.org/10.1016/s1098-2140(03)00024-9

De Roubaix M (2016) The decolonialisation of medicine in South Africa: threat or opportunity? S Afr Med J 106(2):159-161. https://doi.org/10.7196/SAMJ.2016.v106i2.10371

Decoteau CL (2017) The AART of ethnography: a critical realist explanatory research model. J Theory Soc Behav 47(1):58-82. https://doi.org/10.1111/jtsb.12107

DFID (2014) Using SenseMaker to understand Girls' lives: lessons learnt. In: The UK Department for International Development, London http://www.girleffect.org/media?id=3211. Accessed 22 December 2014

Disetlhe K (2014) The curse of being a nyatsi - lover's blood also needs to be cleansed. The Sowetan [internet]. Accessed 8 January 2018 http://www.sowetanlive.co.za/entertainment/2014/11/08/the-curse-of-being-anyatsi-lover-s-blood-also-needs-to-be-cleansed

Dubois R (1961) The mirage of health: utopias, progress and biological change. Anchor Books, New York

Faaui TN, Morgan TKKB, Hikuroa DCH (2017) Ensuring objectivity by applying the mauri model to assess the post-disaster affected environments of the 2011 MV Rena disaster in the bay of plenty, New Zealand. Ecol Indic 79:228-246. https://doi.org/10.1016/j.ecolind.2017.03.055

Flores D, Leblanc N, Barroso J (2016) Enroling and retaining human immunodeficiency virus (HIV) patients in their care: a metasynthesis of qualitative studies. Int J Nurs Stud 62(126-136. https://doi.org/10.1016/j. ijnurstu.2016.07.016

Giddens A (1984) The constitution of society: outline of the theory of structuration. Polity Press, Cambridge

Gyasi RM, Abass K, Adu-Gyamfi S, Accam BT, Nyamadi VM (2018) The capabilities of nurses for complementary and traditional medicine integration in Africa. J Altern Complement Med 24(3):282-290. https://doi.org/10.1089/acm.2017.0133

Heestermans T, Browne JL, Aitken SC, Vervoort SC, Klipstein-Grobusch K (2016) Determinants of adherence to antiretroviral therapy among HIV-positive adults in sub-Saharan Africa: a systematic review. BMJ Global Health 1(4):e000125. https://doi.org/10.1136/bmjgh-2016-000125

Heller J (2015) Rumors and realities: making sense of HIV/AIDS conspiracy narratives and contemporary legends. Am J Public Health 105(1):e43-e50. https://doi.org/10.2105/AJPH.2014.302284 
Hernandez A, Ruano AL, Marchal B, San Sebastian M, Flores W (2017) Engaging with complexity to improve the health of indigenous people: a call for the use of systems thinking to tackle health inequity. Int J Equity Health 16:5. https://doi.org/10.1186/s12939-017-0521-2

Ibeneme S, Eni G, Ezuma A, Fortwengel G (2017) Roads to health in developing countries: understanding the intersection of culture and healing. Curr Ther Res Clin Exp 86:13-18. https://doi.org/10.1016/j. curtheres.2017.03.001

Inayatullah S (1998) Causal layered analysis. Futures 30(8):815-829. https://doi.org/10.1016/s0016-3287(98)00086-x Jayasinghe S (2011) Conceptualising population health: from mechanistic thinking to complexity science. Emerg Themes Epidemiol 8:7. https://doi.org/10.1186/1742-7622-8-2

Kalichman SC, Simbayi L (2004) Traditional beliefs about the cause of AIDS and AIDS-related stigma in South Africa. AIDS Care 16(5):572-580

Leclerc-Madlala S, Green E, Hallin M (2016) Traditional healers and the "fast-track" HIV response: is success possible without them? Afr J AIDS Res 15(2):185-193. https://doi.org/10.2989/16085906.2016.1204329

Legare CH, Gelman SA (2008) Bewitchment, biology, or both: the co-existence of natural and supernatural explanatory frameworks across development. Cogn Sci 32(4):607-642. https://doi.org/10.1080 /03640210802066766

Lynam T, Fletcher C (2015) Sensemaking: a complexity perspective. Ecol Soc 20:14. https://doi.org/10.5751/es$07410-200165$

Makgahlela MW, Sodi T (2016) Cultural conceptions of a bereavement-related illness in a south African indigenous community. J Psychol Afr 26(6):541-545

Mausch K, Harris D, Heather E, Jones E, Yim J, Hauser M (2018) Households' aspirations for rural development through agriculture. Outlook on Agriculture 47(2):108-115. https://doi.org/10.1177/0030727018766940

Mkhwanazi N (2016) Medical anthropology in Africa: the trouble with a single story. Med Anthropol 35(2):193202. https://doi.org/10.1080/01459740.2015.1100612

Mönnig HO (1978) The Pedi. J.L. Van Schaik, Pretoria

Morgan TKKB, Fa'aui TN (2017) Empowering indigenous voices in disaster response: applying the mauri model to New Zealand's worst environmental maritime disaster. Eur J Oper Res. https://doi.org/10.1016/j. ejor.2017.05.030

Moshabela M, Zuma T, Gaede B (2016) Bridging the gap between biomedical and traditional health practitioners in South Africa. South African Health Review 2016(1):83-92

Moshabela M, Bukenya D, Darong G, Wamoyi J, McLean E, Skovdal M, Ddaaki W, Ondeng'e K, Bonnington O, Seeley J, Hosegood V, Wringe A (2017) Traditional healers, faith healers and medical practitioners: the contribution of medical pluralism to bottlenecks along the cascade of care for HIV/AIDS in eastern and southern Africa. Sex Transm Infect 93:e1-e5. https://doi.org/10.1136/sextrans-2016-052974

Nattrass N (2013) Understanding the origins and prevalence of AIDS conspiracy beliefs in the United States and South Africa. Sociol Health Illn 35(1):113-129. https://doi.org/10.1111/j.1467-9566.2012.01480.x

Niehaus I (2007) Death before dying: understanding AIDS stigma in the south African Lowveld. J South Afr Stud 33(4):845-860

Niehaus I (2013a) Averting danger: taboos and bodily substances in the South African lowveld. Crit Afr Stud 5(3):127-139. https://doi.org/10.1080/21681392.2013.837352

Niehaus I (2013b) Confronting uncertainty: anthropology and zones of the extraordinary. Am Ethnol 40(4):651660. https://doi.org/10.1111/amet.12045

Oetzel J, Scott N, Hudson M, Masters-Awatere B, Rarere M, Foote J, Beaton A, Ehau T (2017) Implementation framework for chronic disease intervention effectiveness in Maori and other indigenous communities. Glob Health 13(1):69. https://doi.org/10.1186/s12992-017-0295-8

Pacanowsky M (1995) Team tools for wicked problems. Organ Dyn 23(3):36-51. https://doi.org/10.1016/00902616(95)90024-1

Pascale RT, Millemann M, Gioja L (2000) Surfing the edge of chaos: The laws of nature and the new laws of business. Crown Publishers, New York

Rahill GJ, Joshi M, Hernandez A (2016) Adapting an evidence-based intervention for HIV to avail access to testing and risk-reduction counseling for female victims of sexual violence in post-earthquake Haiti. AIDS Care 28(2):250-256. https://doi.org/10.1080/09540121.2015.1071773

Reid G (2013) Gossip, Rumour and Scandal: The Circulation of AIDS Narratives in a Climate of Silence and Secrecy. In: Dilger H, Ute L (eds) Morality, Hope And Grief: Anthropologies of AIDS in Africa. Berghan Books, New York, pp 192-218

Rickles D, Hawe P, Shiell A (2007) A simple guide to chaos and complexity. J Epidemiol Community Health 61(11):933-937. https://doi.org/10.1136/jech.2006.054254

SANAC (2017) The South African National Strategic Plan for HIV, TB and STIs 2017-2022. South African National AIDS Council, Pretoria http://sanac.org.za/wp-content/uploads/2017/05/NSP_FullDocument_ FINAL.pdf. Accessed 27 January 2018 
Sebata T (2015) The Role of Traditional Healers in the treatment of HIV and AIDS in Tsetse Village: The Case of Mahikeng in the North West Province. master's thesis, North-West University

Serekoane M (2010) The Socio-Cultural Context of Patients Undergoing Antiretroviral Therapy in Petrusberg Hospital: an Anthropological Perspective. master's degree, University of the Free State

Sharp PM, Hahn BH (2011) Origins of HIV and the AIDS pandemic. Cold Spring Harb Perspect Med 1: a006841. https://doi.org/10.1101/cshperspect.a006841

Shirindi M, Makofane M (2015) Ritual impurities: perspectives of women living with HIV and AIDS. African journal for physical, health education. Recreation and Dance 21(3: 2):941-952

Shisana O, Rehle T, Simbayi L, Zuma K, Jooste S, Zungu N, Labadarios D, Onoya D, David A, Ramlagan S, Mbelle N, Van Zyl J, Wabiri N (2014) South African National HIV Prevalence, Incidence and Behaviour Survey, 2012. HSRC Press, Cape Town

Smith ST, Dawson-Rose C, Blanchard J, Kools S, Butler D (2016) "I am normal": claiming normalcy in Christian-identified HIV-infected adolescent and emerging adult males. J Assoc Nurses AIDS Care 27(6): 835-848. https://doi.org/10.1016/j.jana.2016.05.004

Snowden DJ, Boone ME (2007) A leader's framework for decision making. Harv Bus Rev 85(11):68-76

Stacey R (2003) Complexity and group processes: A radical social understanding of individuals. BrunnerRoutledge, New York

Stanifer JW, Patel UD, Karia F, Thielman N, Maro V, Shimbi D, Kilaweh H, Lazaro M, Matemu O, Omolo J, Boyd D (2015) The determinants of traditional medicine use in northern Tanzania: a mixed-methods study. PLoS One 10(4):e0122638. https://doi.org/10.1371/journal.pone.0122638

Statistics New Zealand (2013) Census QuickStats about Māori. Wellington (New Zealand) http:// archivestatsgovtnz/Census/2013-census/profile-and-summary-reports/quickstats-about-maori-englishaspx. Accessed 29 January 2018

Sturmberg JP, Martin CM (2010) The dynamics of health care reform-learning from a complex adaptive systems theoretical perspective. Nonlinear Dynamics Psychol Life Sci 14(4):525-540

Tariq S, Hoffman S, Ramjee G, Mantell JE, Phillip JL, Blanchard K, Lince-Deroche N, Exner TM (2018) "I did not see a need to get tested before, everything was going well with my health": a qualitative study of HIVtesting decision-making in KwaZulu-Natal, South Africa. AIDS Care 30(1):32-39. https://doi.org/10.1080 /09540121.2017.1349277

The Cynefin Centre (2018). The Making of Meaning. Accessed 25 March 2018 www.emergentmeaning.com

UNAIDS (2014) Fast track. Joint United Nations Programme on HIV/AIDS, Geneva http://www.unaids. org/sites/default/files/media_asset/JC2686_WAD2014report_en.pdf. Accessed 12 October 2014

UNDP (2013) Discussion Paper. Innovation in Monitoring and Evaluation. United Nations Development Programme, New York http://www.undp.org/content/dam/undp/library/capacitydevelopment/English/Discussion\%20Paper-\%20Innovations\%20in\%20Monitoring\%20\&\%20 Evaluating\%20Results\%20\%20(5).pdf. Accessed 16 July 2017

Vandormael A, de Oliveira T, Tanser F, Barnighausen T, Herbeck JT (2018) High percentage of undiagnosed HIV cases within a hyperendemic south African community: a population-based study. J Epidemiol Community Health 72(2):168-172. https://doi.org/10.1136/jech-2017-209713

Vu L, Tun W, Sheehy M, Nel D (2012) Levels and correlates of internalized homophobia among men who have sex with men in Pretoria, South Africa. AIDS Behav 16(3):717-723. https://doi.org/10.1007/s10461-011-9948-4

WHO (1946) Constitution of the World Health Organization. World Health Organization, Geneva. http://www. who.int/governance/eb/who_constitution_en.pdf. Accessed 28 January 2018

WHO (2007) Everybody's business-strengthening health systems to improve health outcomes: WHO's framework for action. World Health Organization, Geneva. http://www.who. int/healthsystems/strategy/everybodys_business.pdf. Accessed 3 February 2018

WHO (2009) Systems thinking for health systems strengthening. World Health Organization, Geneva. http://apps.who.int/iris/bitstream/10665/44204/1/9789241563895_eng.pdf. Accessed 18 March 2018

WHO (2013) Traditional Medicine Strategy 2014-2023. World Health Organization, Geneva. http://apps.who. int/iris/bitstream/10665/92455/1/9789241506090 eng.pdf?ua=1. Accessed 27 September 2017

Zuma T, Wight D, Rochat T, Moshabela M (2018) Navigating multiple sources of healing in the context of HIV/ AIDS and wide availability of antiretroviral treatment: a qualitative study of community participants' perceptions and experiences in rural South Africa. Front Public Health 6:73. https://doi.org/10.3389 /fpubh.2018.00073 